\title{
Peculiarities of Structural Transformations in HAZ Metal of Rail Steel M76 Joint Produced by Flash-Butt Welding
}

\author{
Georgy Grigorenko, Valery Kostin, Victor Zhukov and Tetiana Zuber \\ E.O. Paton Electric Welding Institute, NASU, 11 Kazimira Malevicha str., Kyiv, 03680, Ukraine
}

\begin{abstract}
The railway transport is one of the main types of communications in the world. Analysis of service conditions of the most critical elements of the railway transport rolling stock (rails, wheels and tyres) shows that one of the main factors determining their reliability and service life is the structural-phase state of steel, which is formed in the process of its producing. Complication of service conditions leads to the more severe requirements, specified by the consumers, where the high level of strength and hardness should be combined with high values of ductility and toughness. Realization of these requirements is possible only at the integrated approach to the improvement of technology of their production on the basis of profound knowledge in kinetics of austenite decay processes of structure formation and its contribution to the mechanical properties. With the formation of mainly bainite-martensite structures in the HAZ (heat-affected zone) metal of welded joints of these steels and saturation of this region with diffusive hydrogen their susceptibility to the cold cracking is increased. In this connection this work presents the results of investigations of effect of the WTC (welding thermal cycles) on the nature of structural transformations, hardness, static strength and resistance to the formation of cold cracks in HAZ metal of high-strength carbon rail steel M76. For this purpose, the structure and kinetics of transformation of an overcooled austenite was studied using the advanced methods of physical materials science by the modeling of phase transformations in the Gleeble 3800 unit. It was found that the cause of reduction in mechanical properties of welded joints of steel M76 is the formation of regions with a completely martensite structure in the amount of up to $5 \%$. Results of investigations will be applied for the optimizing the technology and conditions of FBW of the advanced rail steels. 10 Ref., 4 Tables, 11 Figures.
\end{abstract}

Key words: High-strength carbon rail steel, austenite decay, ferrite, bainite, martensite.

\section{Introduction}

Over the last decade in the most developed countries of the world the works are carried out on reconstruction and re-innovation of rail road that was caused by a significant increase in the traffic flow, freight traffic density and speed of rolling stock movement. In this case the parts of the increased strength with a higher wear resistance are used. These parts, first of all, include solid-rolled wheels of freight cars, tyres, rail ends of frogs, etc. The railway rails of trunkline and passenger transport are manufactured of M76 grade steel (of open-hearth melting) or M76 (of convector melting) at carbon content, varying in the ranges of $0.71-0.82 \%$, and manganese of $0.75 \%-1.05 \%$ (GOST 24182). The required level of

Corresponding author: Tetiana Zuber, junior researcher, research field: materials Science. strength and ductile properties of rail metal $\left(\sigma_{\mathrm{t}} \geq 1,100\right.$ $\left.\mathrm{MPa}, \delta_{5} \geq 6 \%, \psi \geq 15 \%, \mathrm{HB} \geq 3,210 \mathrm{MPa}\right)$ is provided in their manufacture by using the heat treatment of products (normalization, hardening. high tempering), one of the main methods used for joining of long rail sections $(200-800 \mathrm{~m})$ is the FBW (flash-butt welding). At the E.O. Paton Electric Welding Institute the works are carried out over more than 50 years by a group of researchers under the supervisor of Prof. S. I. Kuchuk-Yatsenko for the development and improvement of the technology and design of the innovation equipment for the FBW of rails under the stationary and field conditions. The welding of rails by arc methods of welding, except the FBW, will be also used during repair works, at restoration surfacing of worn-out surfaces of the rails [1-4].

At the same time the reduction in values of impact 
toughness in the areas of HAZ (heat-affected zone) of welds of rail steels made by FBW was found in some works $[5,6]$. The authors believe that this reduction in impact toughness is connected with a structural-phase and chemical micro-heterogeneity, which is characteristic for weld metal and base metal and manifested in a distinctly expressed anisotropy of its strength and ductile properties. It is shown that areas with the increased content of non-metallic inclusions, oxide films or dispersed phases do not reduce the overall welded joint performance.

It is evident that the WTC (welding thermal cycle) has an effect on structural-phase and chemical heterogeneity of HAZ metal of rail steels. In turn, it is determined by technological conditions of welding and heat treatment of welded joints [1-3, 7-9].

In many cases, for example, in welding of medium-alloyed carbon steels the formation of cold cracks in welded joint can be prevented by proper selection of welding conditions and, as a consequence, conditions of WTC proceeding, at which the more ductile structures are formed, not prone to the brittle fracture.

Analysis of literature data shows that the perfect thermal cycle, from the point of view of formation of optimum structure and mechanical properties in rail welding, is considered to be the cycle at which the HAZ metal overheating does not take place as a result of its fast heating at temperatures above the temperature of beginning of formation of austenite $\mathrm{Ac}_{1}$ and subsequent cooling. The delayed cooling below temperature $\mathrm{Ac}_{1}$ promotes the development of pearlite, and at the higher temperatures, bainite (intermediate) transformations of the overcooled austenite. In this case the number of hardening structures is greatly decreased and the resistance of HAZ metal of welded joints to the delayed fracture is increased.

It is shown in Refs. [1,2] that WTC is greatly differed from the conditions of heat treatment of metals and has its peculiarities. They consist in the fact that the metal heating occurs at rate of 200-250 ${ }^{\circ} \mathrm{C} / \mathrm{s}$, and the time of duration at temperatures above $\mathrm{Ac}_{3}$ is not more than 10-15 s (depending on energy input of welding). Therefore, the homogenization of austenite in the region of HAZ metal overheating occurs not completely, thus leading to the austenite structure, not uniform in composition. At the next cooling, this affects kinetics of structural-phase transformations. As to the effect of WTC on structural-phase changes in HAZ metal of rail steel M76, then the investigations in this direction were not carried out sufficiently $[3,4,7]$.

In Ref. [3] the structural transformations in HAZ metal of rail steel during cooling of joints were studied by using the method of simulation of WTC and thermal analysis. However, given results of Ref. [3] required the further clarifications and more profound investigation of nature of structural transformations in HAZ metal of rail steel joints.

\section{Experimental Section}

\subsection{Materials}

To study the effect of WTC on structural-phase transformations and to reveal the structural causes of reducing the mechanical properties in HAZ metal, the rail steel M76 was selected for use in the flash-butt welding.

\subsection{Method}

Modeling of the WTC was carried out on specimens of rail steel M76 in simulation unit Gleeble 3800. As a result the TKD (thermo-kinetics diagram) of austenite decay was plotted and structure of the simulating HAZ was studied.

The simulation specimens for investigations were obtained after heating of a central part of the specimen up to the temperature $1,200{ }^{\circ} \mathrm{C}$ for $6 \mathrm{~s}$ and subsequent cooling at preset rates of cooling of 5, 8, 12, 20, 30 ${ }^{\circ} \mathrm{C} / \mathrm{s}$ (Table 1), covering the range of typical rates of cooling used in the mechanized welding. Chemical composition and mechanical properties of investigated 
high-strength carbon (rail) steel are given in Tables 2-4.

The TKD of decay of overcooled austenite of steel M76 is presented in Figs. 1a and 1b.

\section{Results and Discussion}

The investigation of structure of specimens-simulators showed that before cooling rate of $1{ }^{\circ} \mathrm{C} / \mathrm{s}$ the structure of simulating HAZ metal consists of ferrite and pearlite. With increase in cooling rate above $4{ }^{\circ} \mathrm{C} / \mathrm{s}$ the sorbite and troostite are formed, and above $6{ }^{\circ} \mathrm{C} / \mathrm{s}$ the martensite is formed. With increase in cooling rate of ferrite and pearlite transformation is reduced from $700{ }^{\circ} \mathrm{C}$ to $500-550{ }^{\circ} \mathrm{C}$. Troostite is formed in the range of temperatures of $480-360{ }^{\circ} \mathrm{C}$. Temperature of beginning of martensite transformation is $200-210{ }^{\circ} \mathrm{C}$.

Basing on the model developed by us [10] the kinetics of austenite decay with time was calculated for the rail steel M76. The calculated number of structural components and nature of changing the structures with time at different cooling rates $(5,12$ and $30{ }^{\circ} \mathrm{C} / \mathrm{s}$ ) is presented in Fig. 2.

Analysis of calculated diagrams shows that at cooling rates of $5{ }^{\circ} \mathrm{C} / \mathrm{s}$ the completely pearlite structure is formed (Fig. 2a). With increase in cooling rate up to $12{ }^{\circ} \mathrm{C} / \mathrm{s}$ the amount of pearlite is decreased to $67 \%$ due to the growth of troostite, sorbite (Fig. 2b). At cooling rate $30{ }^{\circ} \mathrm{C} / \mathrm{s}$ the amount of martensite is about $90 \%$ at a small amount of pearlite (8-10\%) (Fig. 2c).

Table 1 Rate of cooling in HAZ of rail steel M76.

\begin{tabular}{ll}
\hline No. of specimen-simulator & Cooling rate, ${ }^{\circ} \mathrm{C} / \mathrm{s}$ \\
\hline 1 & 5 \\
2 & 8 \\
3 & 12 \\
4 & 20 \\
5 & 30 \\
\hline
\end{tabular}

Table 2 Chemical composition of investigated rail steel M76.

\begin{tabular}{|c|c|c|c|c|c|c|c|c|c|c|c|}
\hline \multirow{3}{*}{ Steel grade стали } & \multicolumn{10}{|c|}{ Elements, wt.\% } & \multirow{3}{*}{$\begin{array}{l}-\mathrm{C}_{\text {eq. }}^{*} \\
-\%\end{array}$} \\
\hline & & & & & & & & & $\mathrm{S}$ & $P$ & \\
\hline & $C$ & $\mathrm{Mn}$ & S1 & $V$ & $\mathrm{Cr}$ & $\mathrm{Nb}$ & $\mathrm{Cu}$ & $\mathrm{N}_{1}$ & \multicolumn{2}{|c|}{ Not more than } & \\
\hline $\begin{array}{l}\text { Rail steel M-76 } \\
\text { (GOST 24182) } \\
\text { as-delivered state }\end{array}$ & $0.71-0.82$ & $0.75-1.02$ & $0.25-0.45$ & $\leq 0.02$ & -- & -- & -- & -- & 0.018 & 0.011 & $\frac{0.8-1.0}{0.93}$ \\
\hline $\begin{array}{l}\text { Investigated rail steel } \\
-76\end{array}$ & 0.74 & 0.85 & 0.30 & -- & 0.15 & $\leq 0.02$ & 0.10 & 0.12 & 0.015 & 0.010 & $\underline{0.96}$ \\
\hline
\end{tabular}

$* \mathrm{C}_{\text {equivalent }}=\mathrm{C}+\mathrm{Mn} / 6+\mathrm{Si} / 24+\mathrm{Ni} / 10+\mathrm{Cr} / 5+\mathrm{V} / 14, \%$.

Table 3 Mechanical properties of investigated rail steel M76 (0.74\% C).

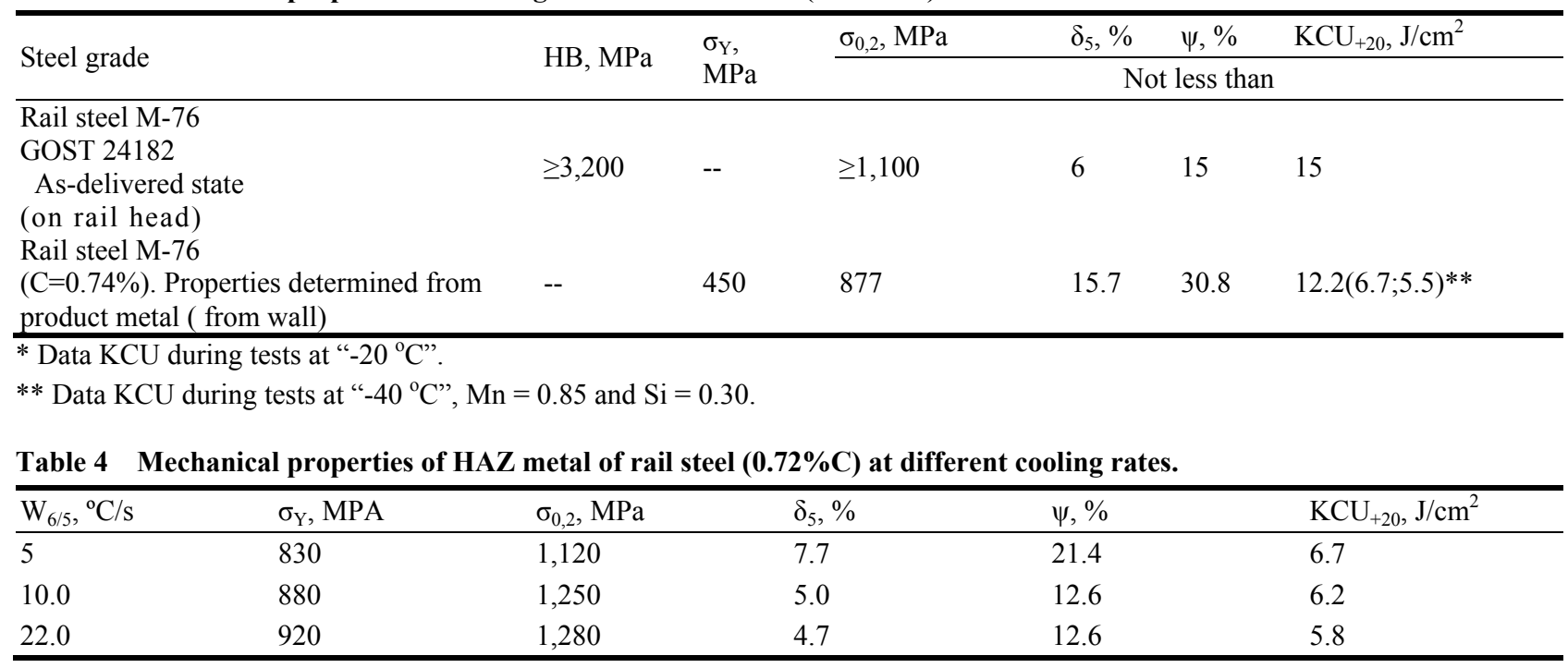




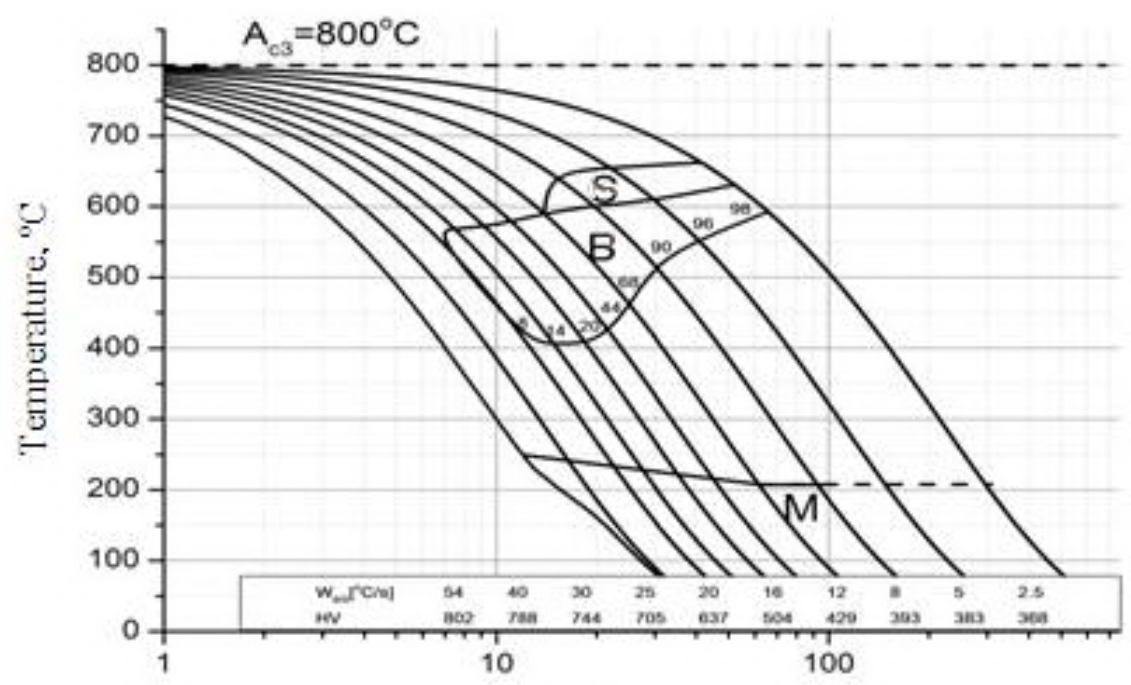

Time of cooling, $\mathrm{s}$

(a)

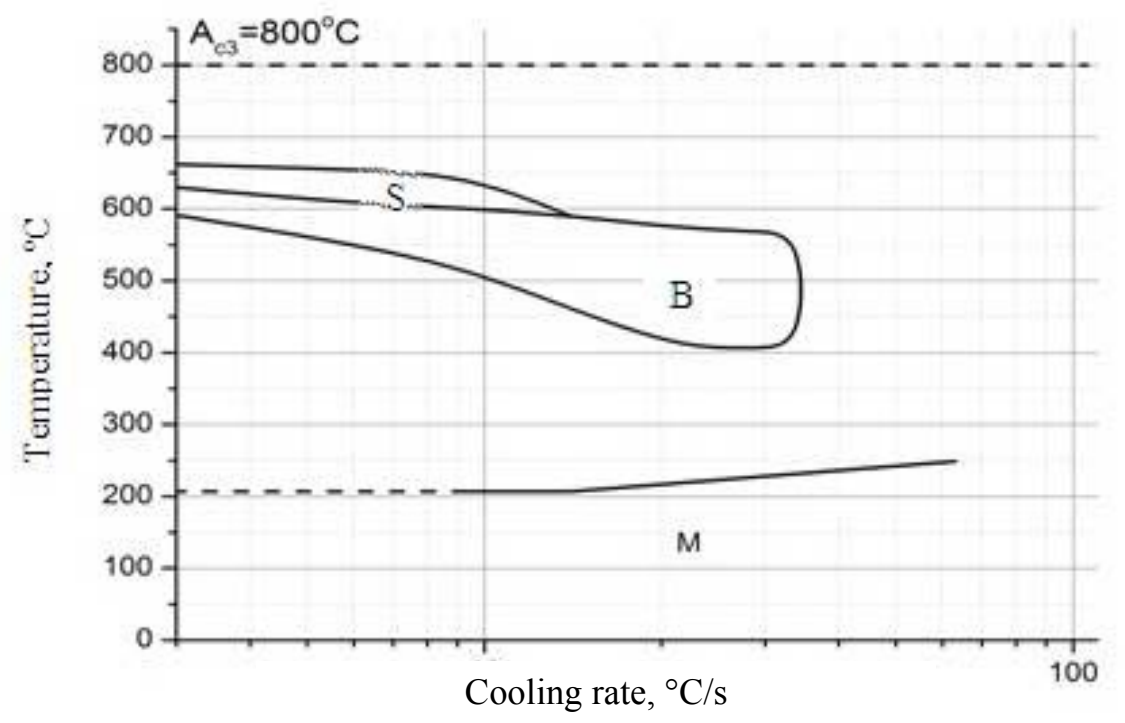

(b)

Fig. 1 Thermokinetic diagrams of decay of austenite of rail steel M76: (a) traditional; (b) in coordinates: temperature-cooling rate $\left(\mathrm{W}_{8 / 5}\right)$ in the range of $800-500{ }^{\circ} \mathrm{C}$.

\subsection{Microstructure of Specimens-Simulators of Steel} M76 after Tests in Gleeble 3800

$$
\text { Metallographic examinations of }
$$

specimens-simulators were carried out by standard procedures. The specimens were manufactured by using diamond pastes of different dispersity on high-speed discs, the examinations were performed on polished specimens for the presence of defects and non-metallic inclusions. Microstructure of specimens was revealed by using chemical etching in $4 . \%$ alcohol solution of nitric acid. Metallographic examinations were made in microscope "Neophot-32" at different magnifications. Grain number was determined by a visual comparison with references of scales (GOST 5639-82). Integral microhardness was measured in microhardness meter M-400 of company "Leco" at $1 \mathrm{~kg}$ load. Microhardness of separate structural components was measured in hardness meter M-400 of "Leco" company at $100 \mathrm{~g}$ load. Digital 


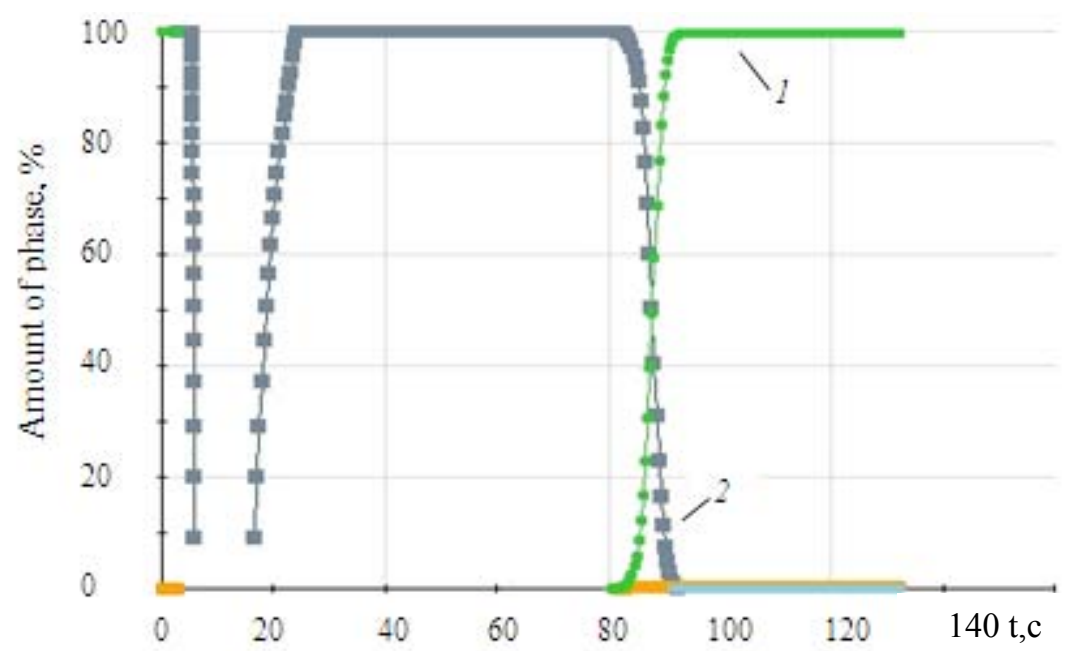

(a)

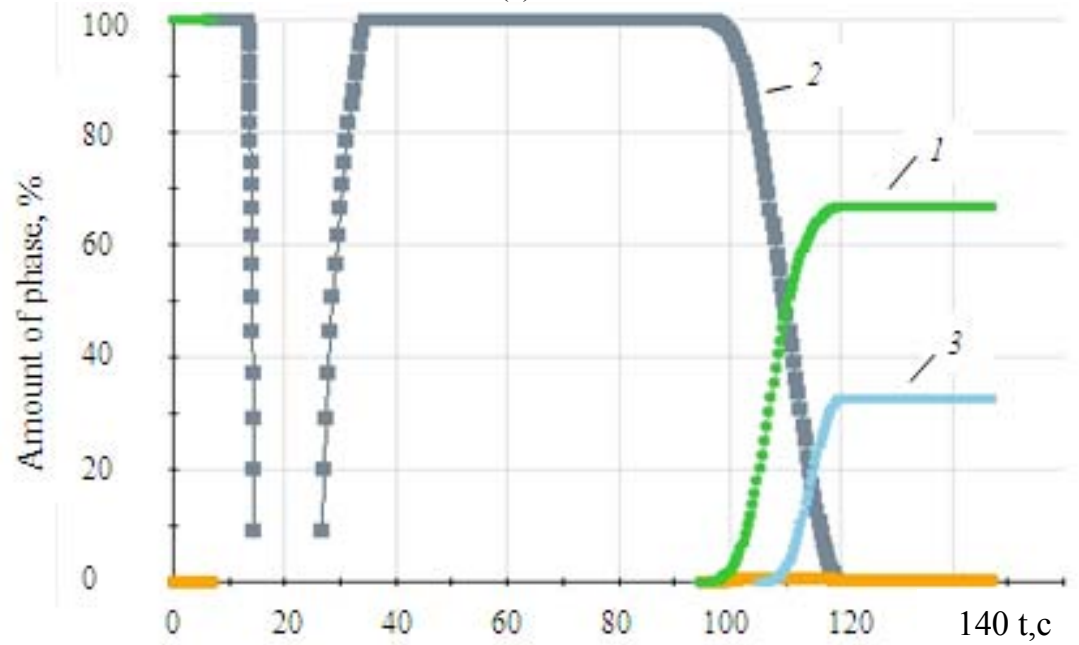

(b)

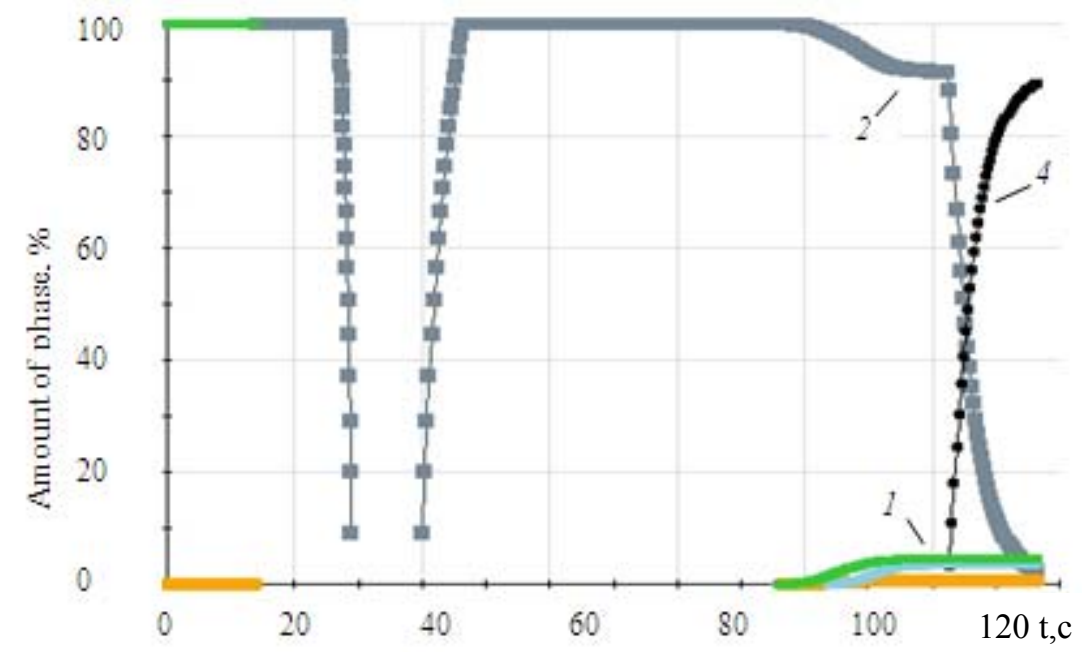

(c)

Fig. 2 Effect of cooling rate of steel M-76 on kinetics of changing the structure with time : (a) $5{ }^{\circ} \mathrm{C} / \mathrm{s} ;$ (b) $12{ }^{\circ} \mathrm{C} / \mathrm{s} ;$ (c) $30{ }^{\circ} \mathrm{C} / \mathrm{s}$ (1-pearlite; 2-austenite; 3 -troostite, sorbite; 4-black is martensite). 
image was obtained by using the photographic camera "Olympus". Calculation of structural components was performed by the standard procedure [2] in optical microscope at magnification $\times 200$ by using a measuring net $(10 \times 10)$. By using this procedure one hundred node points of quadratic net of the ocular are studied in one field of vision. By moving the section in the microscope field of vision, at each new its position the number of node points of the ocular net, incoming into the analyzed structural element, are calculated.

In specimen No. 5, obtained at the highest cooling $30{ }^{\circ} \mathrm{C} / \mathrm{s}$ under conditions of rigid fixture of the specimen-simulator to manifest the deformational (welding stresses) component of welding cycle, the formation of cold cracks, which are located in a central part of the specimen, was revealed, which corresponds to the region of coarse grain of the heat-affected zone. Crack is propagated inside the specimen approximately for one third of the width (Fig. 3a) and developed along the boundaries of the martensite grains (Fig. 3b).

Microstructure of base metal of examined specimens-simulators consists mainly of a lamellar pearlite with small areas of ferrite (Fig. 4a). Grain value is varied from 6 to 7 number by GOST 5639-82, which proves about the structure different grain size. The Vicker's hardness of the base metal is HV0.1

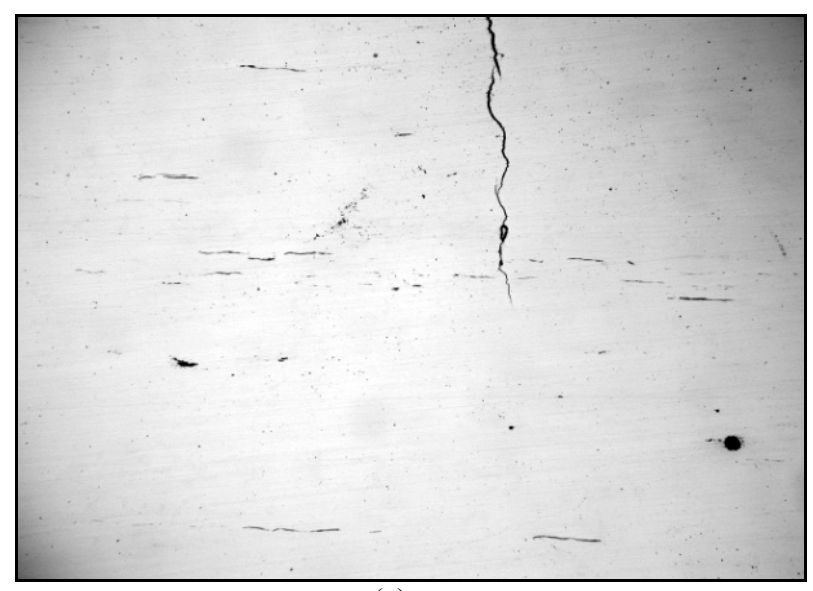

(a)

\section{1,850-2,200 MPa.}

The microstructure of the simulated heat-affected zone of all the examining specimens is characterized by the presence of three clearly expressed regions of: coarse grain (overheating area), fine grain (normalization area) and incomplete recrystallization. A central part of the specimen which corresponds to the region of coarse grain (overheating area) was examined more in detail.

The microstructure of the specimen-simulator No. 1 with the least rate of cooling $\mathrm{W}_{6 / 5}=5^{\circ} \mathrm{C} / \mathrm{s}$ (Fig. 4b) consists of mixture of sorbite, troostite and single grains of martensite. The main part of the structure is mainly troostite in the form of formed rosettes (microhardness of microstructure of troostite is HV0.1 3,360-3,780 $\mathrm{MPa}$ ), located at the background of sorbite (HV0.1 2,970-2,320 MPa), as well as fine rare precipitations of martensite grains with microhardness HV0.1 5,030-5,420 MPa. With increase in cooling rate up to $\mathrm{W}_{5}=8{ }^{\circ} \mathrm{Cs}$ (specimen-simulator No. 2), the well-formed homogeneous troostite structure with single grains of martensite structure is observed unlike the previous specimen (Fig. 4c). Microhardness of microstructure of troostite is HV0.1 3,140-3,780 $\mathrm{MPa}$.

This specimen is characterized by the presence of clearly formed martensite grains (HV0.1 5,620-6,200 $\mathrm{MPa}$ ) in the overheating area.

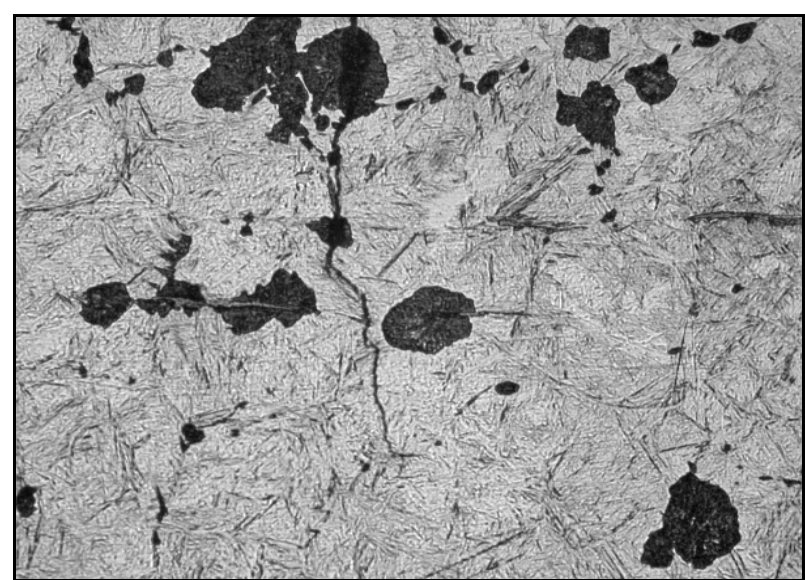

(b)

Fig. 3 Appearance and nature of defect propagation in the examined specimen-simulator $N o .5\left(\mathrm{~W}_{6 / 5}=30^{\circ} \mathrm{C} / \mathrm{s}\right)$ of steel $\mathrm{M} 76$ : (a) appearance of crack, $\times 100$; (b) crack appearance after chemical etching, $\times 500$. 


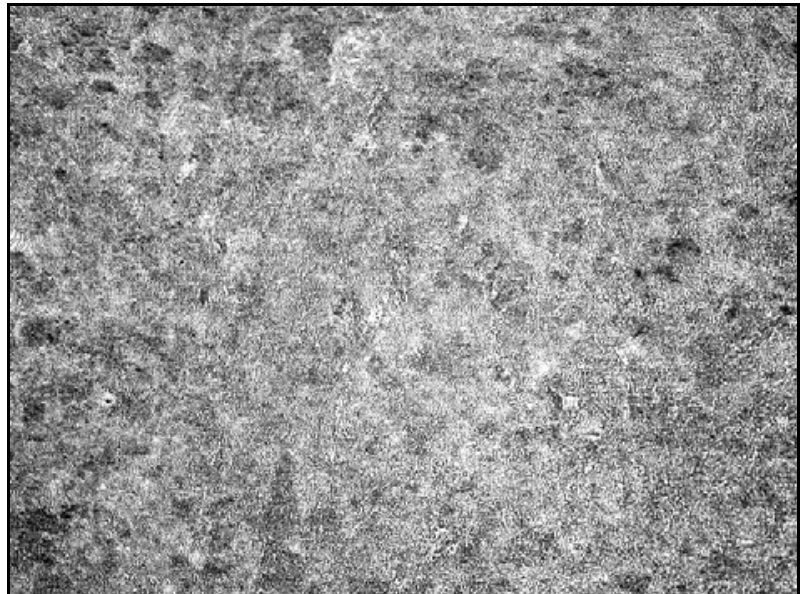

(a)

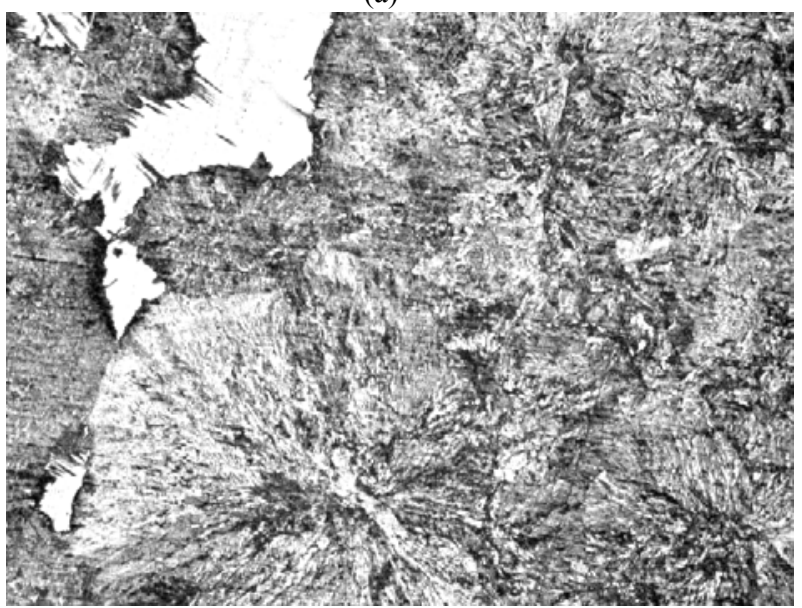

(c)

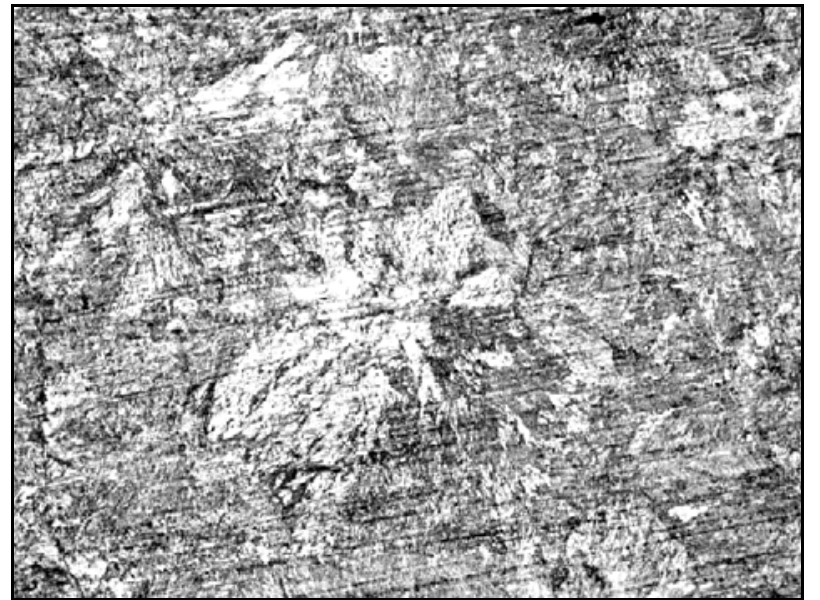

(b)

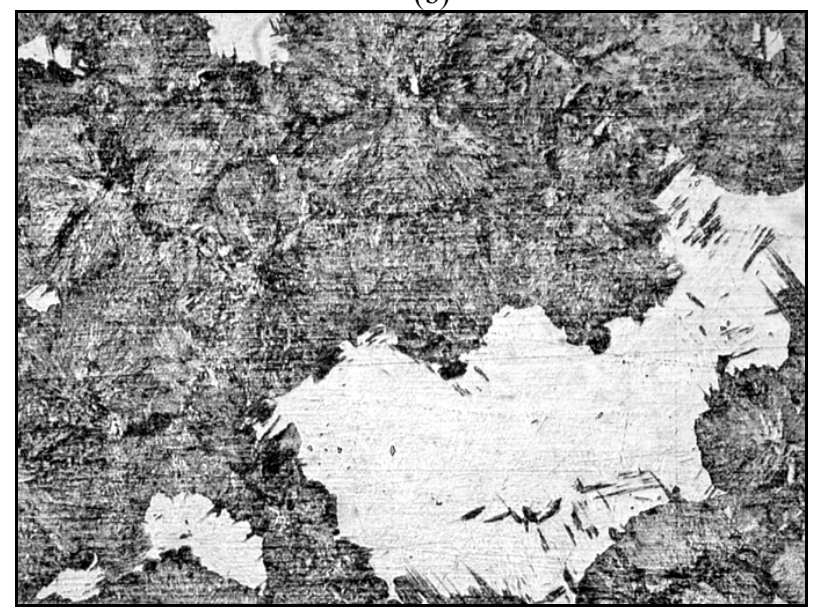

(d)

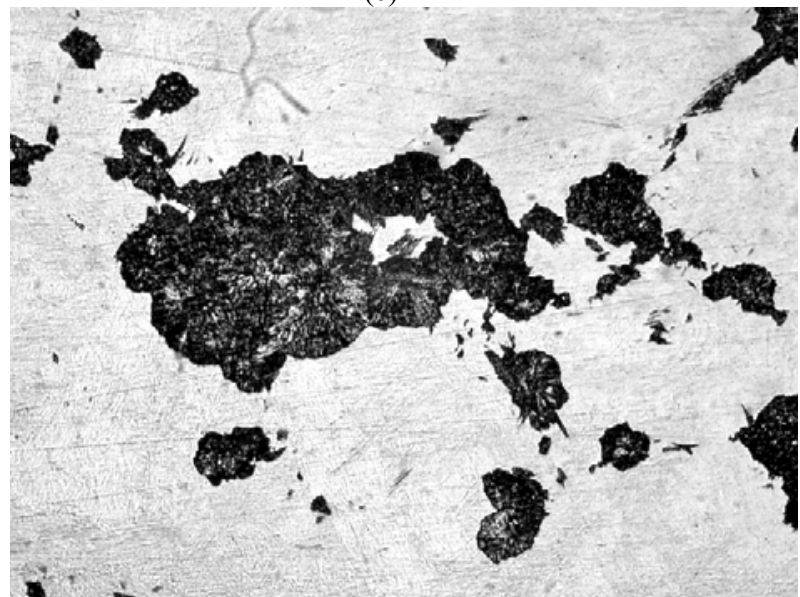

(e)

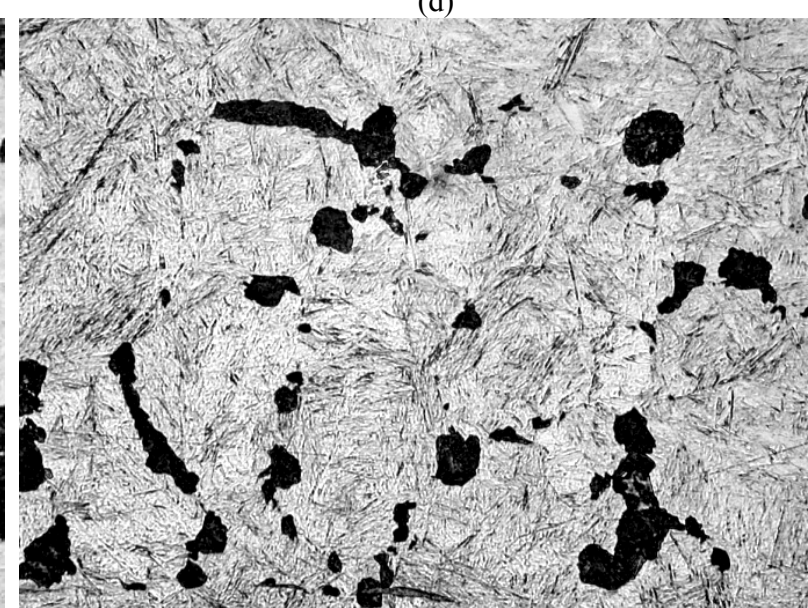

(f)

Fig. 4 Microstructure of base metal $(\times 200)$ and specimens-simulators of $\mathrm{HAZ}$ metal of steel $\mathrm{M76}$ at different cooling rates ( $\times 500$ ): (a) base metal; (b)-(f) are the specimens-simulators; (b) $W_{6 / 5}=5^{\circ} \mathrm{C} / \mathrm{s}$, (c) $W_{6 / 5}=8^{\circ} \mathrm{C} / \mathrm{s},(\mathrm{d}) \mathrm{W}_{6 / 5}=12{ }^{\circ} \mathrm{C} / \mathrm{s}$, (e) $\mathrm{W}_{6 / 5}=20$ ${ }^{\circ} \mathrm{C} / \mathrm{s}$, (f) $\mathrm{W}_{6 / 5}=30^{\circ} \mathrm{C} / \mathrm{s}$.

Microstructure of the specimen simulator No. 3 at cooling rate $\mathrm{W}_{6 / 5}=12^{\circ} \mathrm{C} / \mathrm{s}$ is troostite-martensite with an integral hardness HV1 4,100-4,200 MPa (Fig. 4). In the region of a coarse grain a great precipitation of acicular martensite is observed between troostite rosettes (Fig. 4d). Hardness of martensite is HV0.1 5,150-6,990 $\mathrm{MPa}$, and hardness of troostite is $\mathrm{M}$ HV0.1 3,900-4,010 MPa. Increase in rate of cooling 
up to $\mathrm{W}_{6 / 5}=20{ }^{\circ} \mathrm{C} / \mathrm{s}$ (specimen-simulator No. 4) promotes the formation of martensite-troostite structure. It is smaller amount of troostite in this specimen as compared with the previous specimen and it is located along the boundaries of martensite grains in the form of rosettes (large and small) (Fig. 4e). Hardness of martensite component of structure of specimen No. 4 is changed within the wide range of HV0.1 5,150-7,130 $\mathrm{MPa}$. At the highest rate of cooling $\mathrm{W}_{6 / 5}=30^{\circ} \mathrm{C} / \mathrm{c}$ (specimen-simulator No. $5)$ the acicular martensite structure with rosettes of troostite along the grain boundaries is mainly observed (Fig. 4f). Microhardness of martensite is HV0.1 6,600-7,880 MPa, troostite is HV0 3,380-3,830 $\mathrm{MPa}$ and integral hardness of microstructure is HV1 7,160-7,260 MPa. Effect of cooling rate on the fraction of structural components of martensite-troostite is given in Fig. 5.

The effect of cooling rate on nature of hardness changing along the regions of specimens-simulators of HAZ metal is presented in Fig. 6. The regular increase in integral hardness of region of HAZ metal overheating with increase in fraction of martensite component with increased hardness in the structure of specimens-simulators is observed.

With increase in cooling rate $\left(\mathrm{W}_{6 / 5}=20^{\circ} \mathrm{C} / \mathrm{s}\right)$ the degree of non-uniformity in hardness of examining specimens is growing that is explained by the structural heterogeneity, i.e. regions of martensite component are alternating with troostite regions.

Taking into account the obtained results of investigations and given works in Ref. [3, 4] it can be noted that the HAZ metal in formation of hardening structures in the HAZ overheating region (troostite, martensite) possesses the increased strength properties and low ductility. Moreover, the presence of more than $10 \%$ of martensite leads to an abrupt decrease in resistance of joints to the delayed fracture and formation of cold cracks in the joints. Such metal has a low deformability and, respectively, increased susceptibility to the initiating and developing of cracks. It is possible to improve the ductile properties of the HAZ metal by delaying the welded joint cooling. With decrease in cooling rate to $5{ }^{\circ} \mathrm{C} / \mathrm{s}$, the values of metal ductility is 1.5-2.0 times increased when troostite-sorbite mixture is mainly formed in the HAZ metal overheating zone.

\subsection{Microstructure of Real Welded Joint of Steel M76} Made by $F B W$

Metallographic examinations of real steel M76 welded joint, made by FBW is presented in Fig. 7. Structure of examined regions of the welded joint consists mainly of sorbite of hardness HV0.1-2,400 $\mathrm{MPa}$.

Comparison of structure of specimen-simulator in the area of coarse grain produced at cooling rate of 12 ${ }^{\circ} \mathrm{C} / \mathrm{s}$ and structure of real steel M76 welded joint

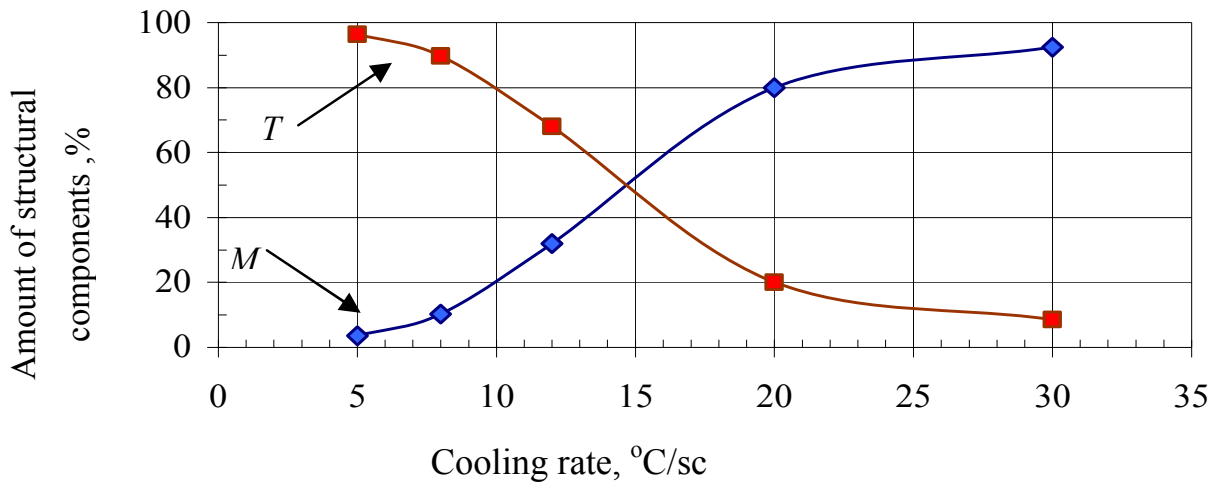

Fig. 5 Dependence of amount of structural components on cooling rate: $M-$ martensite ; $T-$ troostite. 


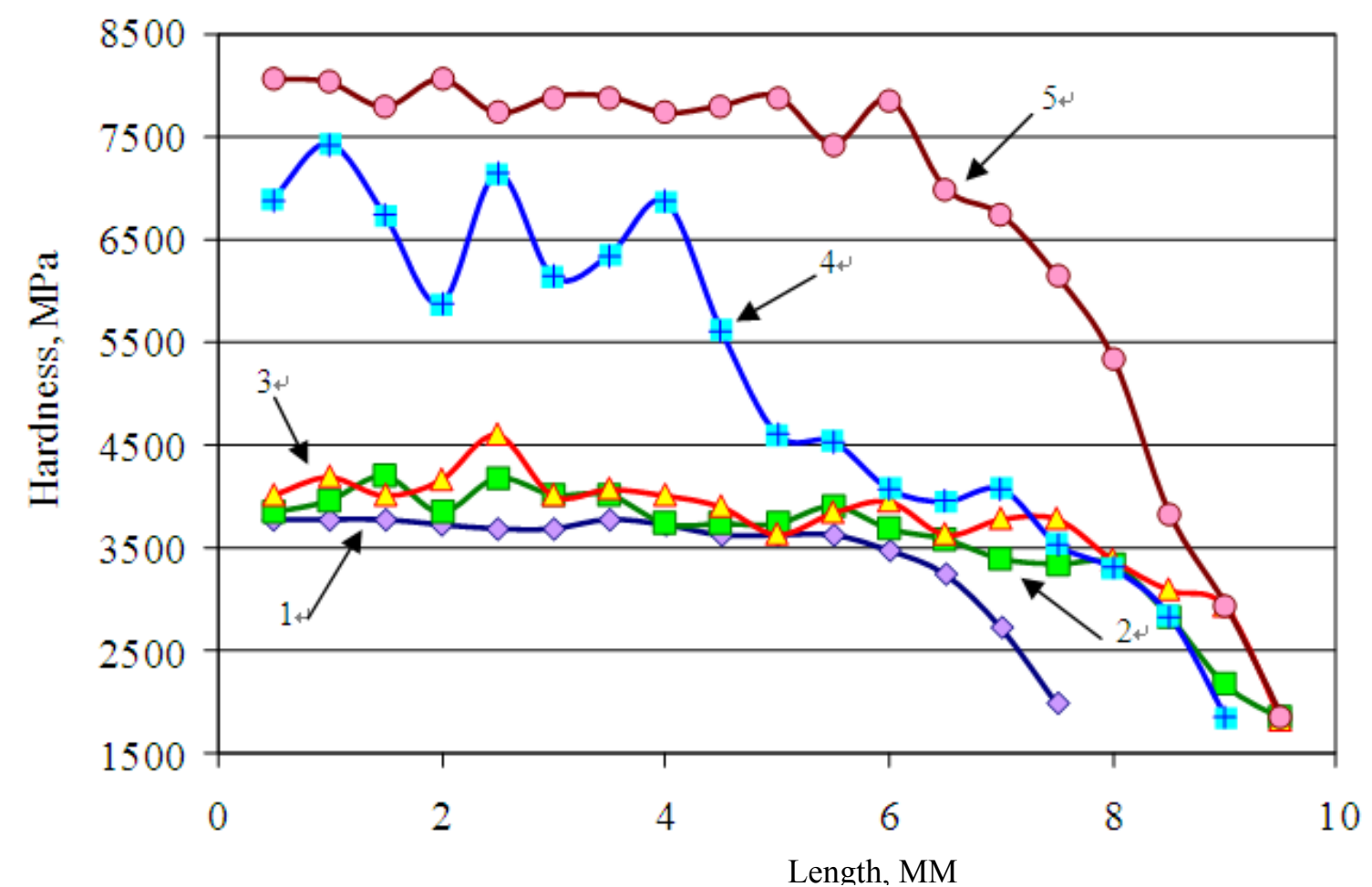

Fig. 6 Effect of cooling rate on nature of hardness changing of examined specimens-simulators in the CGR (coarse grain region): $1-$ cooling rate $5^{\circ} \mathrm{C} / \mathrm{s} ; 2-8^{\circ} \mathrm{C} / \mathrm{s} ; 3-12{ }^{\circ} \mathrm{C} / \mathrm{s} ; 4-20^{\circ} \mathrm{C} / \mathrm{s} ; 5-30^{\circ} \mathrm{C} / \mathrm{s}$.

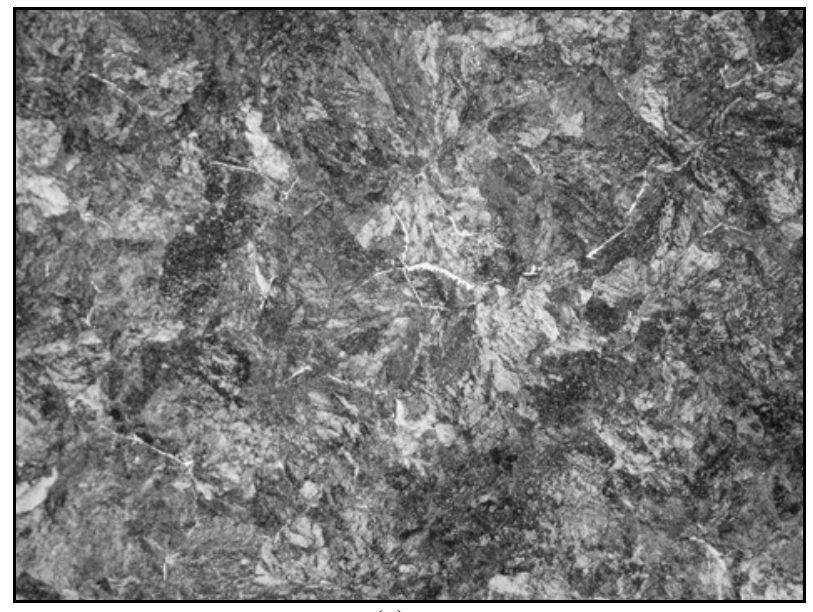

(a)

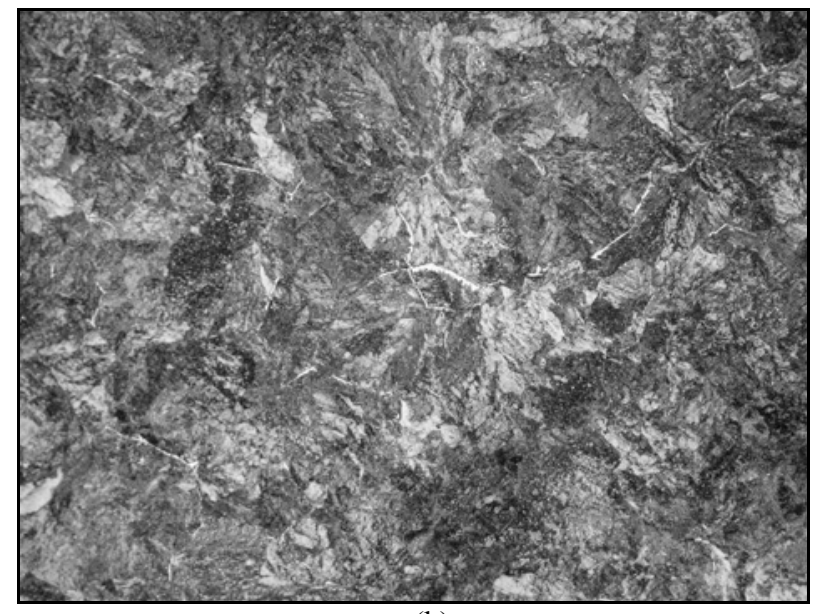

(b)

Fig. 7 Precipitations of hypoeutectoid ferrite along the boundaries of sorbite grains in FBW of steel M76. $\times 200$.

produced by FBW showed their sufficiently good conformity (Figs. 4d and 7a). This confirms once again the efficiency of applying the complex Gleeble 3800 for the adequate modeling of transformations in the structural steels.

In base metal and HAZ metal the fine ferrite precipitations along the boundary of sorbite grains are observed (Fig. 7). In the microstructure of weld metal the fine ferrite interlayers are formed in the larger amount as compared with structure of the base metal and HAZ metal (Fig. 7b).

Hardness of ferrite interlayers in weld metal is varied from HV0.01-1,430 $\mathrm{MPa}$ up to HV0.01-1,680 MPa depending on the interlayer thickness. Probably, due to a large amount of light ferrite precipitations on the etched section the 


\section{Peculiarities of Structural Transformations in HAZ Metal of Rail Steel M76 Joint Produced by Flash-Butt Welding}

so-called "white band" is seen distinctly in the area of contact, in particular at small magnification (Fig. 8).

It was found that in the heat-affected the separate light regions (up to 5\%) with a slightly etched structure are formed (Fig. 9). Moreover, in one case these regions are located near the contact zone along the "white band" (Fig. 8a), and in another case they are located in HAZ metal at some distance from the contact zone (Fig. 9b). Light round areas are arranged in chains along the rolling direction.

Additional intensive etching of welded joint allowed revealing the acicular structure of "light round areas" in the heat-affected zone that can prove the presence of hardening structures in these areas of the zone (Figs. 10a and 10b). Measurement of

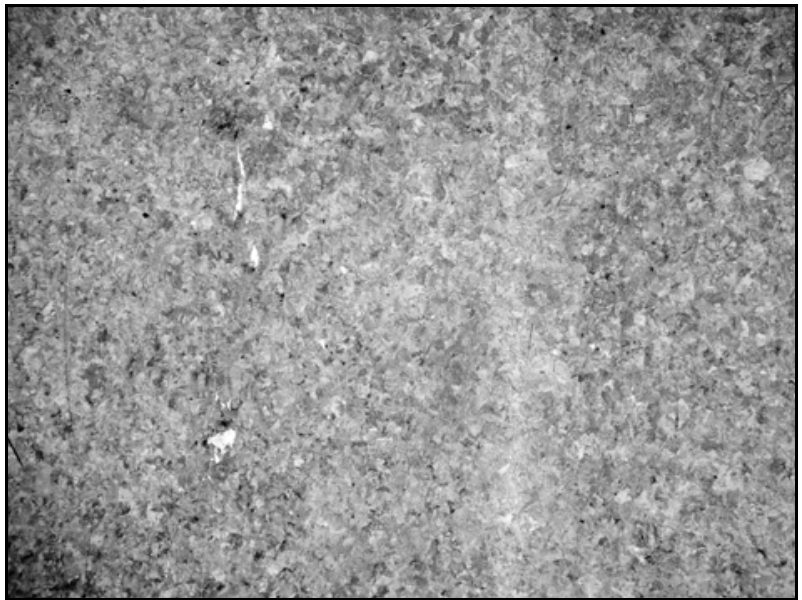

(a)

Fig. 8 "White band" in the contact zone in FBW of steel M76, $\times 25$ hardness confirmed that these regions are the martenste structure of hardness up to HV0.01-6,000-6,060 MPa.

Regions of martensite are located at the distance from 1.0 up to $5.0 \mathrm{мm}$ from the fusion line ("white band"). In initial metal of rails and other regions of welded joint the hardening structures are not formed.

Results of hardness measurement by Vickers across the fusion line of examined specimens at $300 \mathrm{~g}$ load (Fig. 11) showed the increase in hardness in HAZ metal at an abrupt decrease of this value in "white band".

Thus, during investigations the main regularities of formation of structure were established and possible causes of reducing the impact toughness in HAZ metal of rail steel M76 were revealed.

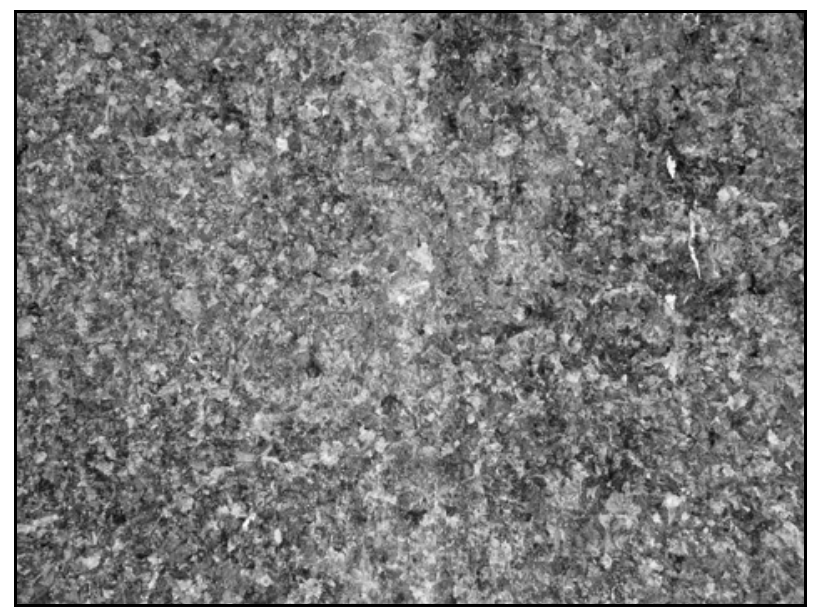

(b)

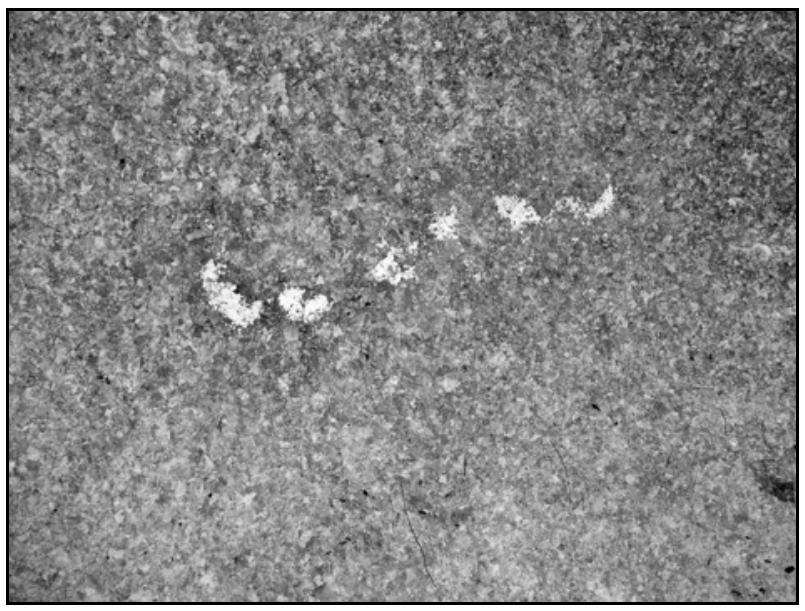

(a)

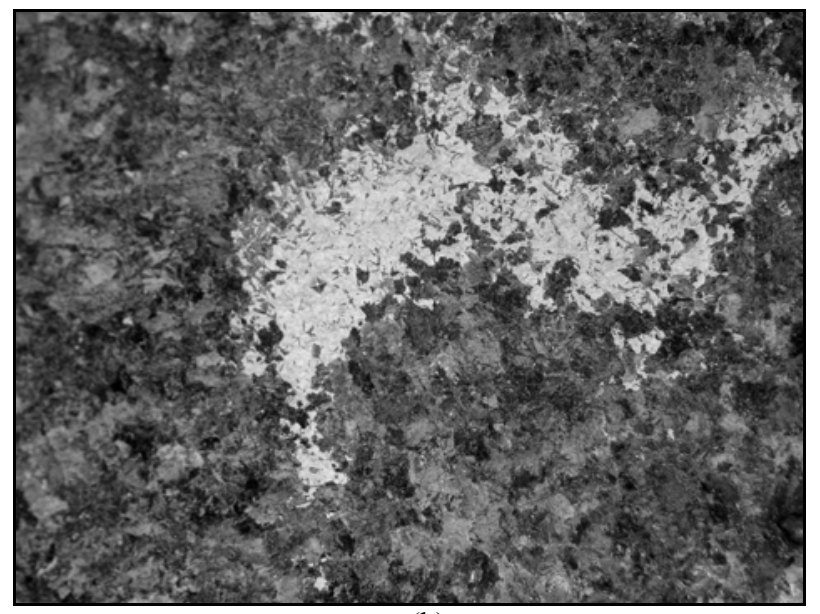

(b)

Fig. 9 Regions of martensite in HAZ metal of rails in FBW. $\times 100$. 

Rail Steel M76 Joint Produced by Flash-Butt Welding

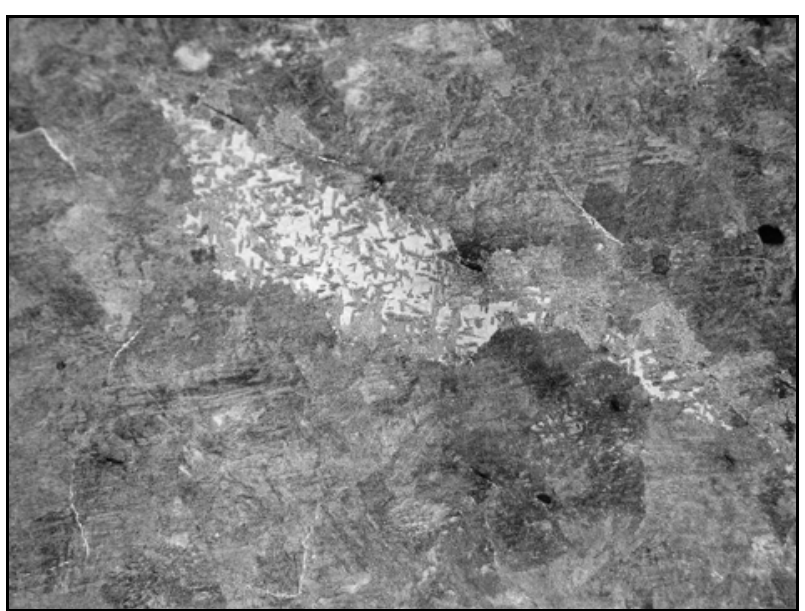

(a)

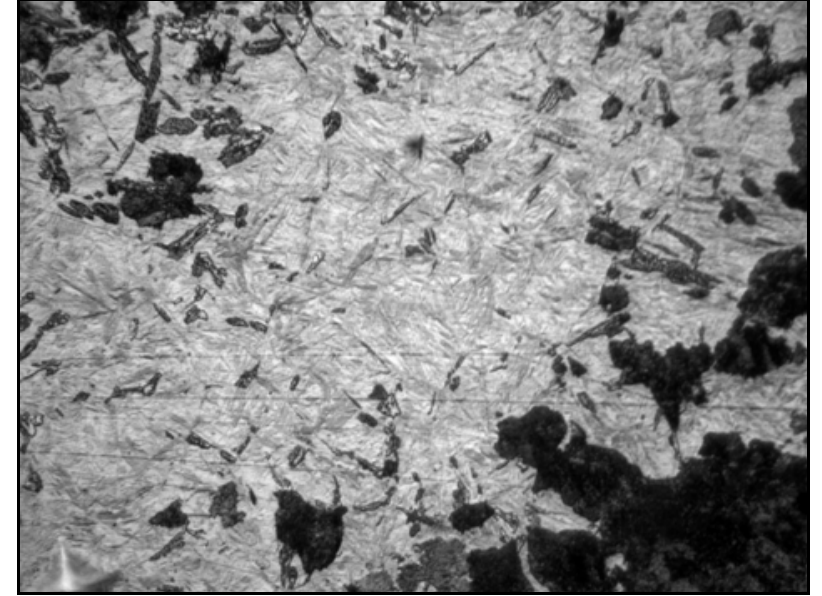

(b)

Fig. 10 Regions of acicular martensite in HAZ metal: (a) $\times 200$; (b) $\times 1,000$.
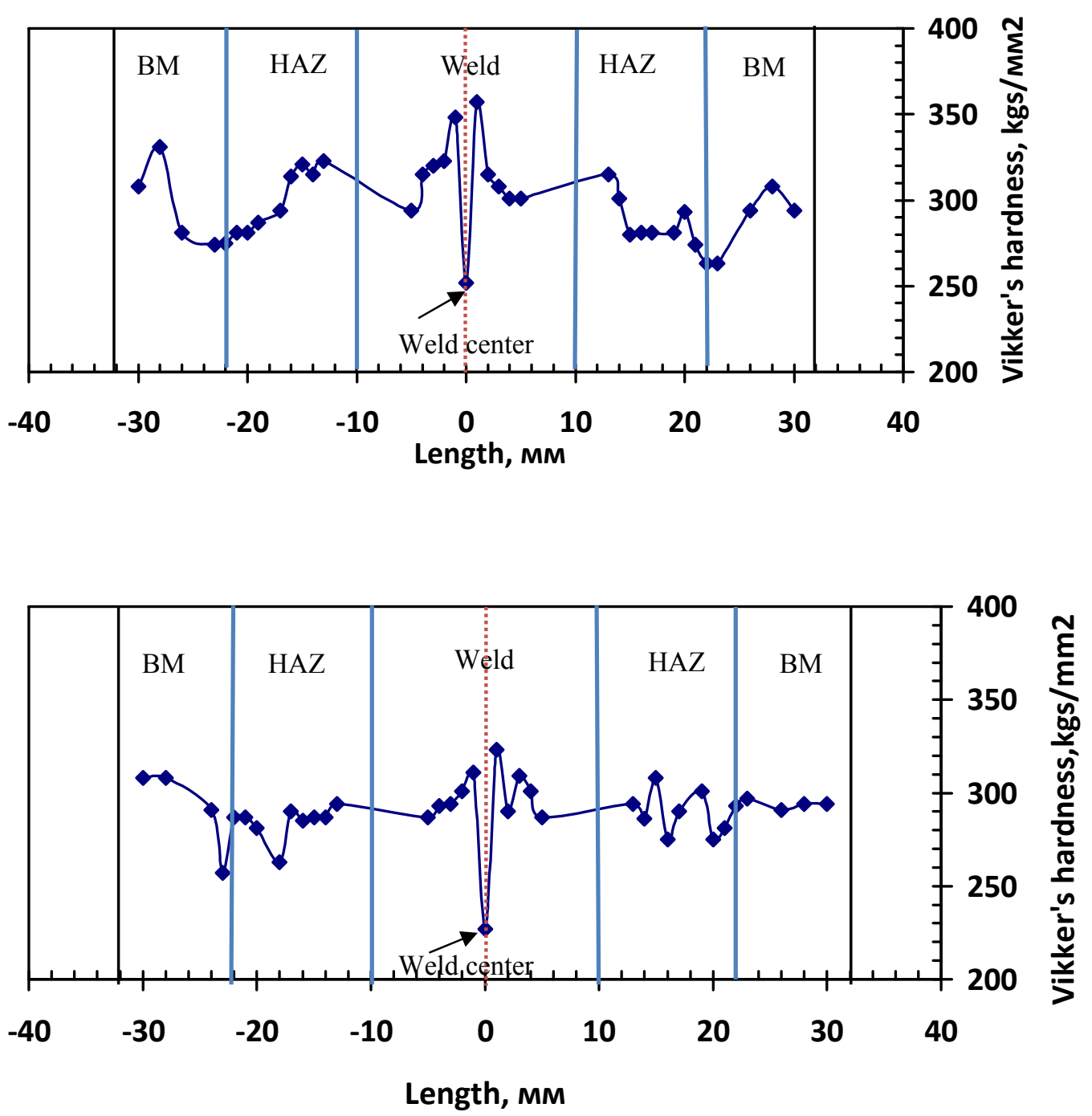

Fig. 11 Nature of change in hardness in FBW welded joints of steel M76. 


\section{Conclusions}

It was found that for specimens of rail steel M76 during the process of simulation of WTC the fraction of martensite component in the metal structure is increased with increase in cooling rate. At low rates of cooling $5-8{ }^{\circ} \mathrm{C} / \mathrm{s}$ the troostite structure is mainly formed which then at rates of cooling $10-12{ }^{\circ} \mathrm{C} / \mathrm{s}$ is transformed into the troostite-martensite structure. At high rates of cooling above $20{ }^{\circ} \mathrm{C} / \mathrm{s}$ the martensite-troostite structure $(80 \%$ martensite and $20 \%$ troostite) is formed, and at $30{ }^{\circ} \mathrm{C} / \mathrm{s}$ it is $92.4 \%$ martensite and $8.6 \%$ troostite).

It is shown that in electric arc welding of rail steel M76 under the conditions of a rigid fixture (restricted deformation) at high rates of cooling $>30{ }^{\circ} \mathrm{C} / \mathrm{s}$ the cold cracks are formed which are located mainly in the coarse grain region of HAZ metal.

It was found that in electric arc welding of rail steel M76 the rate of cooling in HAZ metal should not exceed $8{ }^{\circ} \mathrm{C} / \mathrm{s}$ in the temperature interval $600-500{ }^{\circ} \mathrm{C}$, that can be realized due to applying of increased energy inputs in FBW or by using preheating of joints being welded up to temperature $200{ }^{\circ} \mathrm{C}$ and more. Under these conditions of welding the increased resistance of HAZ metal against formation of brittle cracks is provided.

In the heat-affected zone in FBW of steel M76 the regions with complete martensite structure are formed (in the amount less than 5\%), which lead to the reduction of mechanical properties of welded joints. The regions are located at the distance of $1.0-5.0 \mathrm{~mm}$ from the fusion line and have the higher level of hardness (up to 6,000-6,060 MPa).

\section{References}

[1] Paton, B. E. 1974. Technology of Electric Arc Welding of Metals and Alloys by Fusion. M.: Mashinostroenie, 768.

[2] Grabin, V. F., and Denisenko A. V. 1978. Metals Science of Welding of Low- and Medium Alloyed Steels. K.: Naukova Dumka, 272.

[3] Poznyakov, V. D., Kiryakov, M. D., Gajvoronsky, A. A. et al. 2011. "Effect of Technological Factors on Resistance to Delayed Fracture of Butt Joints of rail steel in Arc Welding.” Avtomaticheskaya Svarka 11: 11-5.

[4] Poznyakov, V. D., Kiryakov, V. M., Gajvoronsky, A. A., Klapatyuk, A. V., and Shishkevich, O. S. 2010. "Properties of Welded Joints in Electric Arc Welding." Avtomaticheskaya Svarka 8: 19-24.

[5] Kuchuk-Yatsenko, S. I., Shvets, Yu. V., Kavunichenko, A. V., Shvets, V. I., Taranenko, S. D., and Proshchenko, V. A. 2015. "Flash-Butt Welding of Railway Frogs through the Cast Austenite Insert." Avtomaticheskaya Svarka 8: 7-9.

[6] Kuchuk-Yatsenko, S. I., Kuchuk-Yatsenko, Yu. V., and Shvets, V. I. 2014. "Effect of Non-metallic Inclusions in Pipe Steels of Strength Class X65-X80 on Values of Impact Toughness of Welded Joints Made by Flash-Butt Welding." Avtomaticheskaya Svarka 12: 5-10.

[7] Chernyak, Ya. P., Bursky, G. V., and Kalensky, V. K. 2002. "Some Peculiarities of Delayed Fracture of HAZ Metal of Steel M76 after Surfacing with Austenite Wire." Avtomaticheskaya Svarka 8: 50-2.

[8] Makarov, E. L. 1981. Cold Cracks in Welding of Alloyed Steels. M.: Mashinostroenie, 247.

[9] Hrivnyak, I. V. 1984. Weldability of steels. M.: Mashinostroenie, 215.

[10] Grigorenko, G. M., and Kostin, V. A. 2013. "Plotting of Diagrams APA on the Basis of Regression Model of Structural Transformations in Welds of High-Strength Low-Alloy Steels." Sovremennaya Elektrometallurgia 1: 33-9. 